\title{
Introducing serious games with Wikis: empowering the teacher with simple technologies
}

Citation for published version (APA):

Van Rosmalen, P., \& Westera, W. (2014). Introducing serious games with Wikis: empowering the teacher with simple technologies. Interactive LearnIng Environments, 22(5), 564-577.

https://doi.org/10.1080/10494820.2012.707128

DOI:

10.1080/10494820.2012.707128

Document status and date:

Published: 03/09/2014

Document Version:

Peer reviewed version

Document license:

CC BY-SA

Please check the document version of this publication:

- A submitted manuscript is the version of the article upon submission and before peer-review. There can be important differences between the submitted version and the official published version of record. People interested in the research are advised to contact the author for the final version of the publication, or visit the DOI to the publisher's website.

- The final author version and the galley proof are versions of the publication after peer review.

- The final published version features the final layout of the paper including the volume, issue and page numbers.

Link to publication

\section{General rights}

Copyright and moral rights for the publications made accessible in the public portal are retained by the authors and/or other copyright owners and it is a condition of accessing publications that users recognise and abide by the legal requirements associated with these rights.

- Users may download and print one copy of any publication from the public portal for the purpose of private study or research.

- You may not further distribute the material or use it for any profit-making activity or commercial gain

- You may freely distribute the URL identifying the publication in the public portal.

If the publication is distributed under the terms of Article 25fa of the Dutch Copyright Act, indicated by the "Taverne" license above, please follow below link for the End User Agreement:

https://www.ou.nl/taverne-agreement

Take down policy

If you believe that this document breaches copyright please contact us at:

pure-support@ou.nl

providing details and we will investigate your claim.

Downloaded from https://research.ou.nl/ on date: 26 Apr. 2023 


\title{
Introducing Serious Games with Wikis: Empowering the Teacher with simple Technologies
}

\author{
Peter van Rosmalen, Wim Westera \\ Centre for Learning Sciences and Technologies (CELSTEC), \\ Open University of the Netherlands.
}

Address for correspondence: Peter van Rosmalen, Open University of the Netherlands, P.O. Box 2960, 6401 DL Heerlen, The Netherlands

Email: peter.vanrosmalen@ou.nl

\begin{abstract}
Despite the continuous and abundant growth of the game market the uptake of games in education has been hampered by the general impression that games require complex technologies and that games are difficult to organise and to embed in education curriculums. This paper explores to what extent a simple serious game scenario that can be easily adopted and adapted by individual teachers and that only uses a common, relatively simple technology can leverage the adoption of serious games. It discusses the design of such a game, Argument, based on a Wiki and its use in a 6 weeks trial by students of a Master of Learning Sciences Programme. The results indicate that, even though a Wiki has clear limitations, it is a useful instrument to build game alike educational activities, to gain experience with and as a first step to use (more) complex serious games.
\end{abstract}

Keywords: Serious games, teacher training, gamification, Wiki-games, Wiki

\section{Introduction}

Games, in general, have a longstanding tradition in education and training, covering a wide variety of application domains: business (Angehrn \& Maxwell, 2009), medicine (Cabas Vidani, Chittaro, \& Carchietti, 2010), language learning (Connolly, Stansfield, \& Hainey, 2011) and many more. Game environments tend to be highly responsive and demanding and thus provoke active learner involvement. They allow for exploration, experimentation, competition and co-operation, while requiring self-regulation, information skills, strategic thinking, anticipation and critical thinking (Pivec, 2007). Although the domestic market of video entertainment games has been a fast-moving field over a number of years, with annual growth rates well above 10\% (PWC, 2010; National Gaming Survey, 2009), the use of games for educational purposes has remained quite limited (Ten Brummelhuis \& Van Amerongen, 2010; Klopfer, Osterweil, \& Salen, 2009). Barriers identified in the literature include lacking 
expertise of teachers, barriers linked with the school system, financial barriers and technical barriers (NFER, 2009). This paper studies the introduction of a game-based learning approach while making an effort to remove financial and technical barriers. We investigated to what extent a free online wiki service can be used for implementing an open game scenario that lives up to the expectations associated with games (Westera, Nadolski, Hummel, \& Wopereis, 2008) and that can be easily used and adapted by the teachers.

First we will briefly explain the theoretical background of game-based learning. Second, we will outline the barriers that teachers experience for adopting games in their classrooms. Third, we will specify the research questions of this study. Fourth, we will specify the game scenario taking into account some basic requirements. Fourth, we will present the research method, while finally we will present and discuss the results.

\section{The Case of Game-based Learning}

From a theoretical point of view two perspectives are of relevance for using games for learning: motivation and instructional design. First, games are assumed to contribute to effective learning because they enhance the learner's intrinsic motivation, which is considered a main determinant of effective learning (Keller, 1983). In most games the player is put in the empowered position of autonomously taking decisions on the course of events. Selfdetermination theory explains how autonomy enhances self-motivation (Ryan \& Deci, 2000). The theory of intrinsic motivation (Malone \& Lepper, 1987) explains that the learners’ motivation can be enhanced by challenge (an appropriate balance between skills and challenge), fantasy (an appropriate level of immersion in a fictitious environment while enacting a particular role with associated responsibilities), curiosity (due to linking a personal challenge or goal in the game to uncertain outcomes) and control (being in charge and responsible). Regarding the continuous feeling of challenge, the high degrees of interaction, the multimodality of content and the freedom of movement offered, these conditions are likely to be met in a game.

Second, from the perspective of instructional design games may reflect behaviourist, cognitivist as well as constructivist models of instruction. In contrast with educational software applications of the 1980s and 1990s, though, which had an emphasis on the first two models, gaming tends to favour constructivist approaches by enabling multimodal, highly interactive, open-ended problem cases, combined with opportunities for collaboration and competition (multi-player games). Relevant theories are experiential learning theory (Kolb, 1984), situated learning theory (Brown, Collins, \& Duguid, 1989; Herrington \& Oliver, 
2000), and social learning theory (Bandura, 1977), which all emphasise the role of context as the driver of learning. According to experiential learning theory the learning is regarded the individual process of making meaning out of the experiences gained in the environment. Situated cognition theory assumes that all knowledge is inherently linked to activities bound to the context of operation. Social learning theory assumes that the social context is the dominant driver for learning via the mechanisms of observation and dialogue. Games seem to conform to the common requirement of these theories by offering an appropriate context for learning.

\section{Barriers for using Games in Education}

Only few data are available describing teachers' opinions on using games in their classrooms. In a survey among 1632 UK primary and secondary school teachers over a third reported that they used games for teaching in their classrooms (NFER, 2009). Sixty percent of the teachers reported that they are prepared to using entertainment games for educational purposes, $21 \%$ said they didn't know and only 19\% rejected the idea. The majority of teachers (85\%) were predominantly positive about what could be learnt or developed as a result of playing computer games. The overall impression is that many teachers are interested in game-based learning, but experience severe barriers for using these in their classrooms. Different types of barriers have been identified in the literature.

\section{Expertise barriers}

Generally teachers have insufficient knowledge about games and their beneficial usage in classrooms (NFER, 2009). Educational games are considered fundamentally different from prevalent instructional paradigms (FAS, 2006). Williamson (2009) reports an urgent need for the training of teachers both at the initial training stage and the stages of continuous professional development, pursuing a better understanding of how to use games in their class rooms as well as understanding the implications of games as cultural forms of young people's lives. Klopfer, Osterweil and Salen (2009) notice that teachers find it difficult to integrate the play of a game within the fixed time structure of their schools.

\section{Systemic barriers}

Klopfer, Osterweil and Salen (2009) blame the school system for their reluctance of giving up text books or purchasing educational technologies that are not clearly linked to existing curriculum standards and the formal assessment standards. Furthermore, within the school system teachers lack the time, incentives and support for this work. Role models that could demonstrate new modes of teaching are avoided. 


\section{Financial barriers}

The high price and lack of licensing agreements for games prohibits many schools from using these resources (Williamson, 2009). For teachers it is difficult to find game contents that match their needs. The education market displays limited sources of funding. Game companies and venture capitalists are unresponsive at investing in risky products, particularly in educational technology markets that have proven to be rarely successful (FAS, 2006).

\section{Technical barriers}

Games as well as game development are inherently complex (Westera et al., 2008). For schools it is difficult to run their own games server or to arrange their own game development. Although increasingly online web-based games are coming available that conform to cross platform browser standards, there is a lack of dedicated equipment, in particular up-to-date video/graphics cards, making it difficult for teachers to use games in their classrooms (De Freitas, 2006). Also, hardly any tools are available for teachers for adjusting existing game contents, for arranging the subscription of their students, for setting up different game runs, for allocating different roles to different students, for monitoring the performances of their students, or for interfering in a game for providing guidance and support.

The study focuses on removing technical barriers and financial barriers by exploring the suitability of a free wiki service for implementing an open game design. The systemic barriers linked with the school system are inherently difficult to tackle. Providing teachers with appropriate training would be a feasible option for removing their lack of expertise, be it that problems of scale, costs, policies and politics will not make this a quick win.

\section{Research Questions}

Rather than enforcing teachers to get acquainted with and adopt complex, multifaceted, immersive and technically highly demanding serious games, we propose to leverage the use of serious games by developing a simple serious game scenario that can be easily adopted and adapted by individual teachers and that only requires access to a common, relatively simple technology. Although games nowadays are commonly associated with complex, immersive worlds featuring high quality graphics and smooth and fast interactions, this is not the only way to consider games. Games such as board games, with a relatively simple set of rules, have been popular for centuries. Also in computer-based games there is a long tradition for simple alternatives ranging from Play by Email games (see for example: http://www.pbm.com/ lindahl/pbm_list/) to all kind of on-line quizzes. Also Wikis are 
promoted for games (see http://webtrends.about.com/od/wiki/a/wiki_game.htm). There are many options for making a serious game, while considering the wiki as a content management system or a shared desktop. A Wiki, essentially, is no more than a website with facilities for creating, editing, linking and navigating web pages. Originally, a Wiki was made with the help of simplified mark-up language. However, nowadays most Wikis are supported by a WYSIWYG text editor. Some Wikis offer additional functionalities, e.g. levels of access rights and tagging. Wikis are around for over a decade and fit very well into the Web 2.0 paradigm of user involvement and user created content. Because of their ease of use and because they allow users to be actively involved they are widely used in education for a variety of applications (see e.g. Ayers \& Ortega, 2010; Riehle \& Bruckman, 2009) ranging from notes sharing, collaborative writing, exchange of ideas, e-portfolios, shared learning tasks, getting used to ICT, writing multi-media essays and project reports and alike. Popular Wiki-sites such as e.g. Wetpaint (http://wikisineducation.wetpaint.com/) and Wikispaces (http://educationalwikis.wikispaces.com/) assist teachers by offering free accounts and extensive ideas and references on how to use a Wiki in education. Because of their ease of use and their wide-spread availability Wikis are a good starting point for teachers to get acquainted with game-based learning approaches.

While aiming at the removal of financial and technical adoption barriers, the basic research question of this study is to what extent simple and free wiki services can be used for introducing serious games in education. More specifically, research questions are:

- Is it feasible at all to create appropriate and representative game scenarios in a wiki?

o And connected, how could any flaws of using a wiki for gaming be compensated for?

- Is there any learning and/or motivation effect?

- What are the teachers' and learners' experiences; and how do they appreciate the use of a wiki for gaming? In more detail:

o Does the wiki game live up to the learner's expectations about gaming?

o To what extent do teachers (and learners) learn to appreciate game-based learning?

o To what extent do teacher want to learn more about serious gaming, and are prepared to overcome technical barriers?

\section{Requirements for and Design of the Game Scenario}

In order to enable appropriate pedagogical flexibility the serious game scenario is assumed to meet the following requirements. It should: 
- be flexible with regard to the domain of study; to different types of learning goals; and to the usage of various generic game concepts;

- enable constructive collaboration and competition;

- facilitate progress and performance monitoring;

- offer a game play easy adjustable or extendable.

Within the scope of these requirements we designed an argumentation game called Argument. The design of Argument follows a so-called collaborative script (Kobbe et al., 2007) and it fits in with computer supported collaborative learning in general and the use of wiki's as a teaching tool in particular (see e.g. (Parker \& Chao, 2007) and (Stahl, Koschmann, \& Suthers, D. 2006)). Argument's implementation, in principle, does closely follow all aspects of a serious game (see section "Results and Discussion” for a definition). However, when compared to other games or collaborative scripting games (e.g. Hummel et al., 2011), in practice, Argument is probably better described by stating that it makes use of gamification elements (Raymer, 2011; http://en.wikipedia.org/wiki/Gamification: "Gamification is the use of game design techniques and mechanics to solve problems and engage audiences”). Since it does follow a set of game-like rules including collaboration and competition between the participants, however, it does not contribute anything graphical or immersive and its interactions are relatively limited and not typically game-specific.

The Argument game (figure 1) makes use of the collaborative nature of a Wiki, while different groups of students will produce argumentations either in favour or against preset propositions and mutually rate the quality of their argumentations. It intends to promote the learners' ability to get into the details of a chosen topic, i.e. to find and connect information on a topic, to discuss and defend a topic from a given position, and to disprove counterarguments raised by their opponent.

For a start the teacher should draw up a proposition directly linked with the relevant domain of study (which could in principle be any domain). The Argument game then uses four rounds:

- In round 1, the learners -in teams- write a short essay on the position proposed either pro or contra.

- In round 2, the teams write five arguments in favour of their position. Two of their arguments they may strengthen by adding a link to a reference. Moreover, they may use one "cheat" argument (an argument that sounds valid but is not) which gives, if convincing enough to be accepted by the opposing team, additional points. 
- In round 3, the teams challenge the arguments of their opponents.

- Finally, in round 4 the teams write their final, short essay summing up the arguments in favour of their position.

In each round a team can gain points for its contribution. A Hall of Fame is administered to show the team scores. All details of the game are explained in the Wiki including team compositions, position to defend or oppose, background resources, game rules, scores and scoring. Finally, each round is followed by a discussion either in a forum in the Wiki or in the class room (the full details of the game including the manual are available in the game template - in Dutch - at: http://wiki-games-argument-sjabloon.wikispaces.com/).

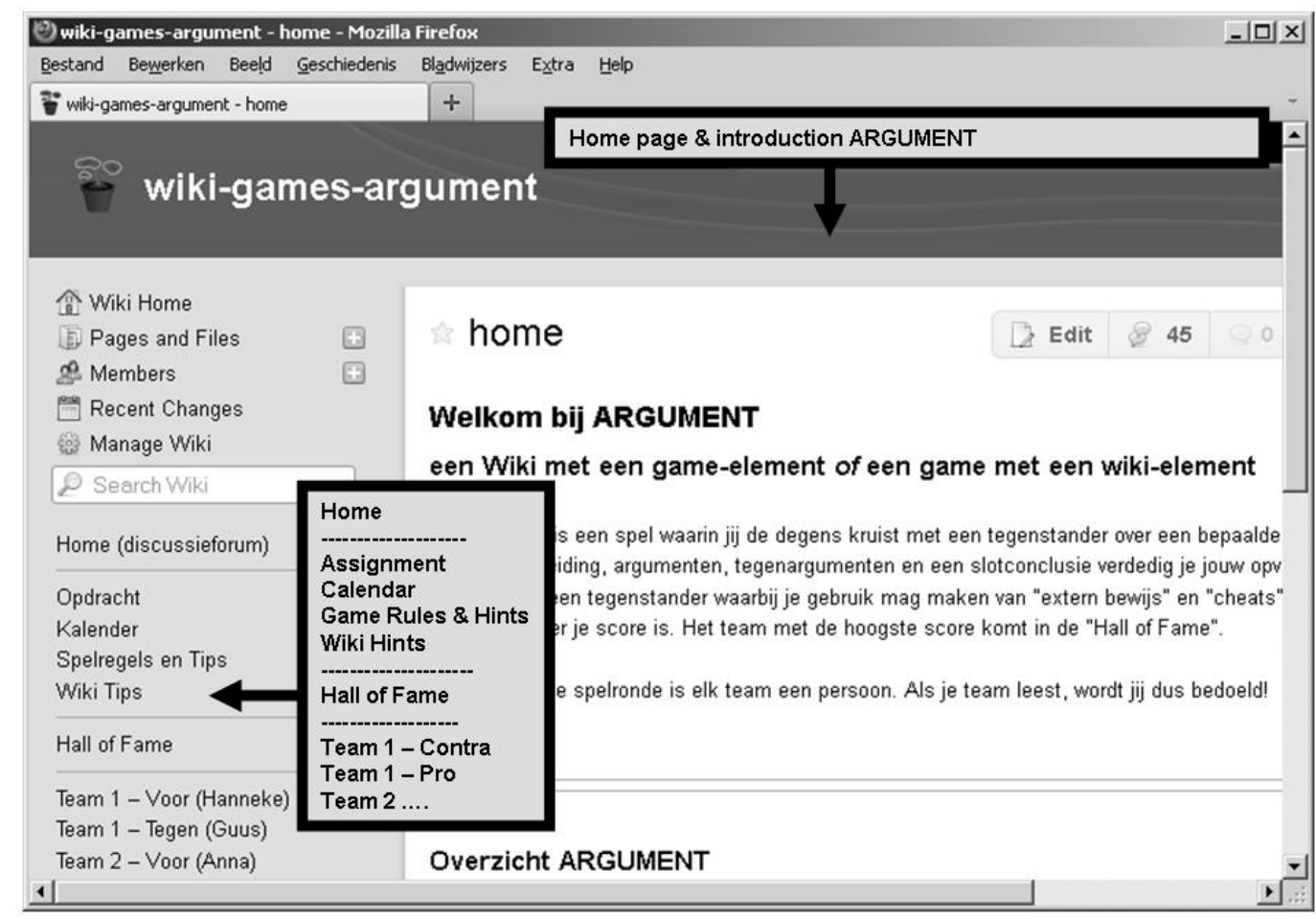

Figure 1.The Wiki-game ARGUMENT home page with at the left its navigation pane.

The Argument game has been implemented in a Wiki of Wikispaces (www.wikispaces.com). For alternatives see for instance http://en.wikipedia.org/wiki/Comparison_of_wiki_software, or http://www.wikimatrix.org/. The game did only make use of the basic tools of the Wiki. Although, it may be easy and straightforward to extend a Wiki with extra widgets, it was decided not to do so in order not to complicate the technical demands on the teachers. This implies that all game logic and scoring is only described in writing. The rules and scoring, as in an 'old fashioned' board game, have to be followed manually by the learners and the teacher. Obviously, an ICT-skilled teacher may opt to add some additional tools. In the same 
line, the rules and scoring of Argument can easily be adapted to accommodate specific needs or desires.

\section{Method}

The participants were students of a Master Programme of Learning Sciences at a distance teaching university. All of them participated in study 1 . Approximately half of them also participated in study 2, as will be explained below. The majority of these students have regular jobs as teachers in schools. Two separate studies based on qualitative research design were carried out, reflecting the learner perspective and the teacher perspective, respectively. In study 1, an instantiation of Argument was evaluated by participants in their roles of learners. Although, in principle, any domain could have been chosen for this study, we focused on the very domain of serious games. This because the participants were expected to have little prior experience with technology enhanced learning in general and with games in particular. Discussing serious games should enable them to give a more well informed contribution to the studies they were involved in.

The main research question investigated was to what extent the learners perceived Argument as a serious game (motivating and instructive). Also, general usability aspects such as ease of use and the quality of the instructions were studied. In study 2, the template version of Argument was used by participants in their roles of teachers to develop their own version of Argument or a derived Wiki-game scenario. In this study the most important questions to be explored were to what extent the teachers were able to use and adapt the template version and could apply it in their educational practice. As part of the evaluation the following data were collected:

- The contributions to the forum including the discussions on the use of and experience with Argument (study 1).

- Progress information (as compared to plan and planning) and questions for assistance via email (study 1).

- A questionnaire on the background of the participants and their participation in study 1 and study 2. The questionnaire consisted of open questions for collecting the students' reflections on their experiences and closed questions asking for the agreement/disagreement on selected statements.

- The designs created by the students (study 2). 
For study 1, the template version of Argument was instantiated with links to background articles on the topic of serious games and for each team the following propositions were given:

- Team 1 - pro: Your team definitely is in favour of serious games in education. Argue and document why you are in favour of the use of serious games in education.

- Team 1 - against: Your team is completely opposed to serious games in education. Argue and document why you are against the use of serious games in education.

Argument was launched together with a time schedule (indicating for each activity when it should be completed and by whom), the allocation of participants to teams and roles, and a forum for each round to discuss the results and the evolution of the game. A forum was used since the flexibility of asynchronous communication made a good match with the limited availability of the participants who lived all over the country and had regular jobs. To start the discussions, for each round individual participants were selected and instructed to open the discussion with a brief reflection.

For study 2, the general version of Argument was extended with a manual including a detailed description of Argument, an explanation of the Wiki functionalities used and an explanation on how to create and instantiate new versions of Argument including suggestions for variations on Argument and alternative ideas for Wiki-games.

The test persons were recruited by an open invitation mailing among students of the Master Programme two weeks before the start of the study. The participants could volunteer to participate in study 1 only or in both study 1 and study 2 . The participants in study 1 were randomly distributed over teams and in each team again randomly assigned to take the role of either argue in favour or argue against the proposition given. In study 2 the participants worked individually. For part 1 of the study 16 students volunteered; 7 of these also participated in study 2 . The average age of the participants ( $n=13,2$ no replies) was 39 years (ranging between 24 -54). There working career was on average 7 years, divided over Higher Education (5), Secondary Education (1), Primary Education (3), Company training (3) or Educational consultancy (1). Their experience with Wikis ranged from none (10) to limited experience (3). In the same line their experience with serious games varied between no experience (8) to limited experience (5). 


\section{Results and Discussion}

\section{Study 1}

In study 1, 15 (4 male, 11 female) of the 16 students actually started. In 3 weeks time the four rounds of the game were played following a strict schedule. Eleven participants completed all 4 rounds; the others completed 2 or 3 rounds. The average estimated time spent on the game was approximately 8 hours. The main findings based on the game contributions, the discussions ( 8 of the participants engaged in 5 discussion threads with in total 40 contributions) in the forum and the questions for explanation or support by email were the following:

- In general both the quality and quantity of the contributions in Argument was good. As indication: the average length in words of the introduction and the conclusion (excluding references and void-contributions) was respectively 200 and 164 words (suggested length for each being 200 words). Moreover, the participants did make regular use of external references to support their point of view, i.e. over 40 references were used, the majority to scientific journals/reports. The discussions indicated that the use of Argument was contributing well to gaining insight both in the topic debated (the use of serious games in education) and in debating itself as pursued by Argument. As one student stated: "I had to defend a proposition I do not agree with. This was a good exercise to think critically on my own viewpoints”. However, the participants also converged into the opinion that Argument only partly lived up to their expectations of a game. Argument posed too much emphasis on serious contributions and both the graphical and the interaction design were considered too limited for evoking a game experience. Some quotes from the discussions on the forum, summarise this very well. One student states: "Nevertheless when I look at this Wiki-game, I notice that I learn a lot of it ... I think that it definitely has added value above traditional educational designs ... However, maybe it should not be called a game”. In the same line a student stated in the first week: “.. For me this game is not sufficiently engaging”. Nevertheless, the same student stated in week 3 at the end of the game play: “ ... I learned a lot and I am considering to use it in my work ... ”.

- Availability problems of the participants in the virtual setting of Argument (game, discussion and support) caused some delays and waiting times. On average approximately $20 \%$ of the contributions was delayed. This synchronisation problem disrupted both the planning of the participants' work and their experience of the game. 
The questionnaire largely confirmed these findings. First, we confronted the participants with our working definition of a serious game: "Multi-user online serious games are (mostly) competitive, situation-dependent, interactive digital (learning) environments based on a set of rules and / or an underlying model, which, subject to certain restrictions, under uncertainty, a challenging (learning) goal is being pursued for which cooperation is essential” (Nadolski et al., 2006). Next, we asked them to what extent Argument met this definition and alternatively, what their perceptions of Argument were. While at the definition level there was some agreement between the participants whether or not Argument is a game, at the perception level the majority clearly did not see Argument as a game (). Interestingly, the participants do believe that Argument is a good and instructive work format (figure 3). The latter is confirmed when asked how they perceived their learning. Nine of the 13 respondents (4 neutral) to the questionnaire indicated that their involvement with Argument had a clear, positive effect on their knowledge on serious gaming. Finally, the majority of the participants found Argument easy to play (7 positive, 3 neutral, 1 negative) and the instructions clear (7 positive, 2 neutral, 3 negative).

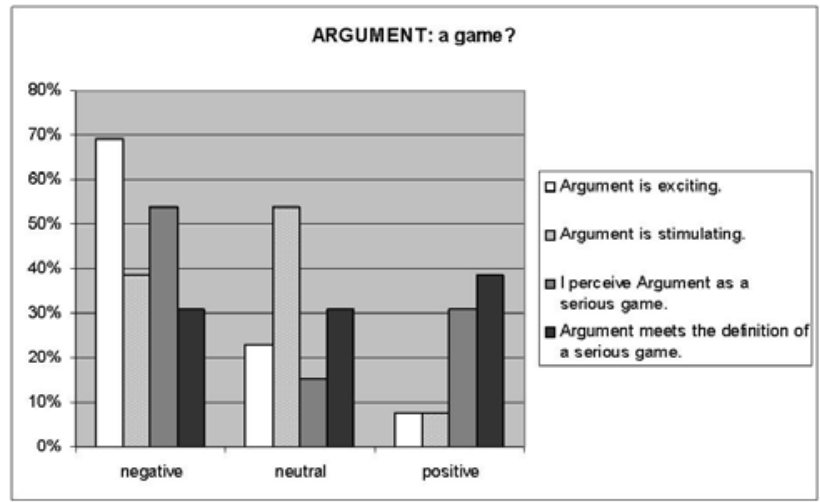

Figure 2. The game element of Argument ( $n=13,2$ no replies).

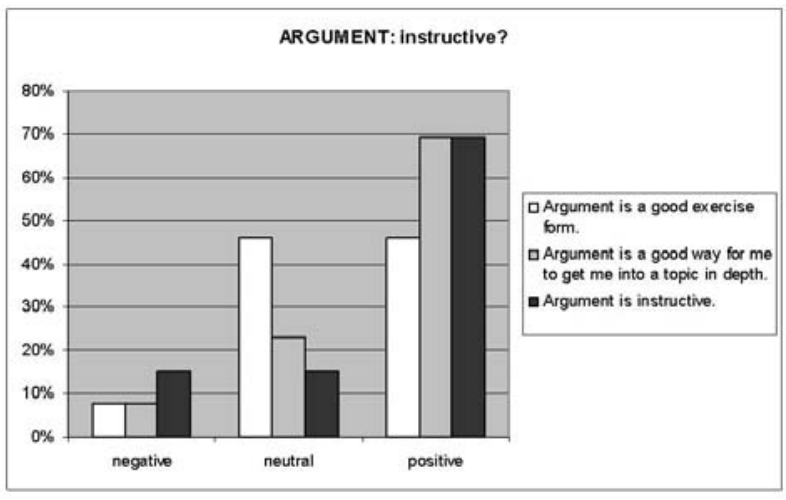

Figure 3. The instruction element of Argument ( $n=13,2$ no replies).

\section{Study 2}

In study 2, 7 students participated in the role of teacher. All of the participants were also involved in study 1, so there were acquainted with Argument. In this study they worked independently to create their own Wiki-game and were asked to complete this assignment within a period of 4 weeks. At the end of the period, 5 participants had completed the assignment, 4 of them created a full version and 1 concentrated mainly on suggestions for improvements, 2 participants were still working on it. 
The topics chosen for their Wiki-games ranged from how to spell verbs (primary education), radiology, liberty of speech to research methods (higher education). There was a variety of implementations ranging from minor modifications to new designs inspired by Argument. The modifications (improvements) concerned:

- The tool used. One participant opted for Google sites. The motivation was that the functionality of Wikispaces was seen as too limited, in particular the possibilities to make a more advanced graphical design.

- The gaming element. A number of attempts were made to improve the gaming element:

o Each player was allowed to choose their own individual topic within one central theme, this to avoid interdependencies between the players.

o Extra bonus points for e.g., delivering in time; making the assignment of another team in case of their delivering too late; the quality of the writing itself.

o The use of an anonymous guest player to avoid dead locks in case contributions are too late.

The participants confirmed in the questionnaire that it was fairly easy for them not only to create a Wiki-game but also to apply it in a useful manner to an educational learning context. A Wiki was seen as a useful tool, with only one remark: the copying of pages, necessary to implement the game structure, was relatively time consuming. The major concern raised, in line with the observations of study 1 , was that presenting Argument as a game was likely too much for 'spoiled' (i.e. used to challenging immersive games) students. Therefore, not surprisingly, also from their perspective as teachers, the overall appreciation was negative for the game element of Argument (3 negative, 3 neutral, 1 positive) and positive for the instructive element (1 negative, 6 positive).

\section{Study 2: Werk!Woord!}

In the period following study 2 one of the wiki-games, i.e. Werk!Woord!, was further developed and evaluated with a group of 12 children (Bronk, 2011). Verb spelling in Dutch is relatively complex and requires a lot of exercise. Pupils, in general, are not very motivated to improve their knowledge and skills in spelling. Though important, spelling is not very challenging to learn. A Wiki-game was designed in which the pupils in small groups competed on their spelling knowledge and skills. Alternating, they had to propose 6 sentences with in one sentence a verb spelling mistake. Their opposing team had to detect the spelling mistake and argue why it was wrong according to a set of spelling rules graphically depicted in a decision flow chart. The Wiki-game was conducted in three rounds. The evaluation included a pre- and a post-test. The use of this Wiki-game was successful in two ways. First, 
it clearly motivated the pupils to learn the verb spelling. Nine out of the 12 pupils indicated that they liked Werk!Woord! and 10 out of 12 that it was instructive. Secondly, both the spelling and the understanding of how to spell improved. The score improved from $63 \%$ correct in the pre-test to $72.5 \%$ correct in the post-test. And interestingly, the explanations on how the spelling was performed also improved from $28 \%$ to $97 \%$. Finally, it is importance to notice that, similar as in the two studies described above, 6 of the 12 pupils indicated that Werk!Woord! in their perception is not a game, because as they state they learn something or because it is seen as an assignment on spelling.

\section{Study 1 and Study 2}

The final judgement of the participants on Argument, either as a player or as player and teacher, was positive despite all the inherent limitations. A larger part of the participants indicated that Argument did inspire them to start using Wikis and other (easy to use) ICT tools, as an introduction to using serious games, or use Argument or a variation of it directly (figure 4). Three participants eventually chose to further engage themselves in this topic and to use the approach for a project in one of their courses of the Master Programme of Learning Sciences.

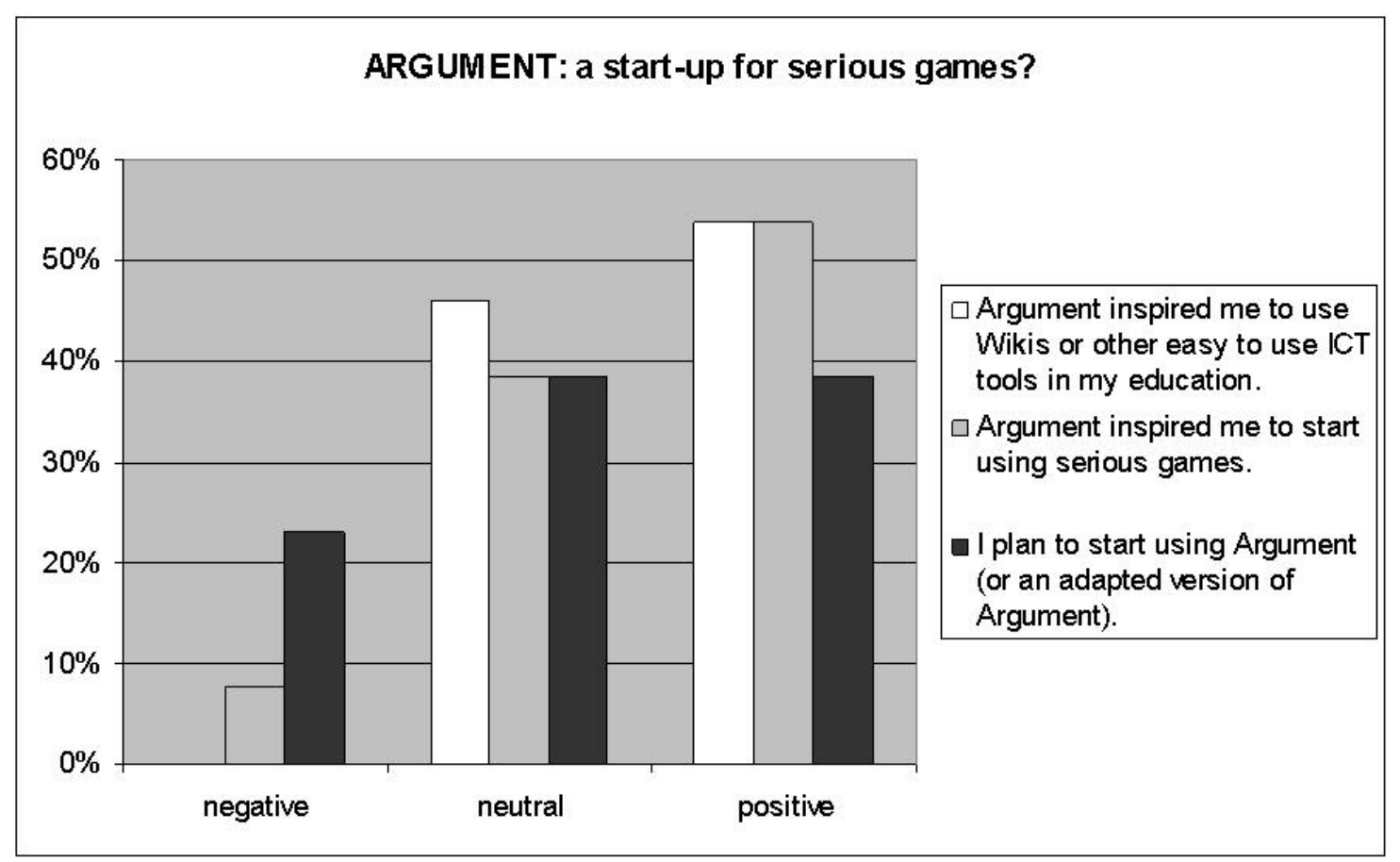

Figure 4. Argument as a way to get introduced to serious games ( $n=13,2$ no replies). 


\section{Conclusion}

The research in this paper started from the observation that the uptake of serious games, despite its anticipated positive effects, is still limited. We focussed our studies on addressing the high, technical demands and the limited familiarity of teachers with games. For this, we investigated to what extent a Wiki could be used by individual teachers to develop and run a serious game; if there would be a positive effect on learning and/or motivation; and what are the teachers' and learners' experiences; and how do they appreciate the use of a wiki. The results demonstrate that a Wiki is an appropriate tool for developing interactive exercises with game-alike characteristics. The learner study indicates that Argument, the Wiki-game developed, enables the learner to get a good understanding of a chosen subject and supports the acquisition of complex skills such as arguing. Moreover, that it is possible to develop other Wiki-games with quite a different topic, such as verb spelling, successfully. However, at the same time, it is clear that a Wiki-game does not meet the learners' expectations of a serious game, created by commonly available games. For Argument, this may be partly due to the fact that the virtual setting imposed, with its tight time schedule, did have a negative impact on the overall experience. To some extent, this may be remediated by making use of the improvements as has been suggested in the teacher study, such as additional bonus points or an anonymous guest player. However, also the evaluation of the other Wiki-game, Werk!Woord!, did reach a similar conclusion. Nevertheless, despite its inherent limitations, both Wiki-games received a positive appreciation. Argument and Werk!Woord! were clearly valued as being instructive. Werk!Woord!, without the virtual settings constraints, was also clearly valued as being motivating. The teacher study indicated that Argument was easy to adapt and adopt to the individual teacher's needs. Moreover, the participants of the studies indicated that Argument did inspire them to start using Wikis and Argument itself and that being actively involved in the Wiki-game Argument was useful as an introduction to start using serious games. Together, obviously within the constraints of small, mainly qualitative studies, the studies indicate that the use of Wikis as discussed can be successfully used to build game alike activities (gamification) and to gain experience with serious games.

\section{Acknowledgments}

We would like to thank John van der Baaren, teacher of the Master Programme, who assisted us with inviting the students and gave feedback on the initial version of Argument. The students of the Master Programme of Learning Sciences of the Open University of the Netherlands who volunteered in their own scarce free time and of them, in particular, San 
Bronk who continued her work and further developed and evaluated Werk!Woord!. The work presented in this paper was partly funded by SURFnet/Kennisnet in their programme 'Innovation of Higher Education 2010 Serious Gaming’.

\section{References}

Ayers, Ph., \& Ortega, F. (Eds) (2010). Proceedings of the 6th International Symposium on Wikis and Open Collaboration 2010. Gdansk, Poland, ACM.

Angehrn, A.A., \& Maxwell, K. (2009). EagleRacing: Addressing Corporate Collaboration Challenges Through an Online Simulation Game. Innovate, Journal of Online Education, vol 5., Issue 6, Aug/Sept 2009.

Bandura, A. (1977). Social Learning Theory. New York: General Learning Press.

Bronk, S. (2011). Projectverslag Wiki Werk!Woord! Project Actief Leren O35241 (Project report Wiki Verb conjugation), Master Onderwijswetenschapen, Open Universiteit, Heerlen, The Netherlands. Unpublished Project Report.

Brown, J.S., Collins, A., \& Duguid, S. (1989). Situated cognition and the culture of learning. Educational Researcher, 18(1), 32-42.

Cabas Vidani A., Chittaro L., \& Carchietti E. (2010). Assessing nurses' acceptance of a serious game for emergency medical services. Published in: Proceedings of VS-GAMES 2010: 2nd International Conference on Games and Virtual Worlds for Serious Applications, IEEE Computer Society Press, Los Alamitos, CA, USA, March 2010, pp. 101-108.

Connolly, T.M., Stansfield, M., \& Hainey, T. (2011). An Alternate Reality Game for Language Learning: ARGuing for Multilingual Motivation. Computers and Education, Volume 57, Issue 1, August 2011, pp 1389-141.

De Freitas, S. (2006). Learning in immersive worlds. A review of game-based learning. Jisc: London, Retrieved from http://www.jisc.ac.uk/media/documents/programmes/elearninginnovation/gamingreport _v3.pdf

FAS (2006). Harnessing the Power of Video Games for Learning. Summit of educational games. Washington DC, Federation of American Scientists. http://www.fas.org/gamesummit/Resources/Summit\%20on\%20Educational\%20Games. pdf

Herrington, J., \& Oliver, R. (2000). An instructional design framework for authentic learning environments. Educational Technology Research and Development, 48(3), 23-48. 
Hummel, H.G.K., Van Houcke, J., Nadolski, R.J., Van der Hiele, T., Kurvers, H., \& Löhr, A. (2011). Scripted collaboration in gaming for complex learning: Effects of multiple perspectives when acquiring water management skills. British Journal of Educational Technology, 42(6), 1029-1041. doi:10.1111/j.1467-8535.2010.01122.x

Kobbe, L., Weinberger, A., Dillenbourg, P., Harrer, A., Hämäläinen, Häkkinen, P., \& Fisher, F. (2007). Specifying computer-supported collaboration scripts. Computer-Supported Collaborative Learning, 2, 211-224.

Kolb, D.A. (1984) Experiential Learning: Experience as the Source of Learning and Development. Prentice-Hall, Inc., Englewood Cliffs, N.J.

Keller, J.M. (1983). Motivational design of instruction. In C. M. Reigeluth (Ed.), Instructional-design theories and models: An overview of their current status. Hillsdale, NJ: Lawrence Erlbaum Associates.

Klopfer, E., Osterweil, S., \& Salen, K. (2009). Moving Learning Games Forward, Obstacles Opportunities \& Openness, Cambridge MA: MIT/The Education Arcade. Retrieved from http://education.mit.edu/papers/MovingLearningGamesForward_EdArcade.pdf

Malone, T.W., \& Lepper, M.R. (1987). “Making learning fun: A taxonomic model of intrinsic motivations for learning,” In R. E. Snow \& M. J. Farr Aptitude, learning, and instruction: III. Conative and affective process analysis. Hillsdale, NJ: Erlbaum, 1987, pp. 223-253.

Nadolski, R. J., Van der Hijden, P., Tattersall, C., \& Slootmaker, A. (2006). Multi-user online serious games: Beleid, ontwerp en gebruik (Multi-user online serious game: Policy, design and use). DU TOGA. Utrecht: Stichting Digitale Universiteit.

National Gaming Survey (2009). Detailed data of gaming in the Netherlands. Newzo, TNSNIPO. Retrieved from http://www.nationaalgamingonderzoek.nl.

NFER (2009). Teacher Voice Omnibus Survey retrieved from NFER: Berkshire. Retrieved from http://www.nfer.ac.uk/nfer/what-we-offer/teacher-voice/PDFs/futurelab.pdf Parker, K.R. and Chao, J.T. (2007) Wiki as a Teaching Tool. Interdisciplinary Journal of Knowledge and Learning Objects, Volume 3, 2007.

Pivec, M. (2007). Editorial: Play and learn: potentials of game-based learning. British Journal of Educational Technology, 38: 387-393. doi: 10.1111/j.1467-8535.2007.00722.x

PWC (2010). Global Entertainment and Media Outlook: 2010-2014. Retrieved from http://www.pwc.com/.

Raymer R. (2011) Gamification: Using Game Mechanics to Enhance eLearning. eLearn Volume 2011 Issue 9, September 2011. ACM New York, NY, USA. 
Riehle, D., \& Bruckman, A. (2009). Proceedings of the 5th International Symposium on Wikis and Open Collaboration 2009. Orlando, Florida: ACM.

Ryan, R., \& Deci, E. (2000). Self-determination theory and the facilitation of intrinsic motivation, social development, and well-being. American Psychology, vol. 55, no.1, pp.68-78.

Stahl, G., Koschmann, T., \& Suthers, D. (2006). Computer-supported collaborative learning: An historical perspective. In R. K. Sawyer (Ed.), Cambridge handbook of the learning sciences (pp. 409-426). Cambridge, UK: Cambridge University Press.

Ten Brummelhuis, A., \& Van Amerongen, M. (2010). Vier in Balans Monitor 2010: Ict in het onderwijs: de stand van zaken (Monitor 2010: Ict in education: the state of affairs). Kennisnet. Retrieved from http://onderzoek.kennisnet.nl/vierinbalansmonitor.

Westera, W., Nadolski, R., Hummel, H. \& Wopereis, I. (2008). Serious Games for Higher Education: a Framework for Reducing Design Complexity, Journal of ComputerAssisted Learning, 24, 5, p. 420-432.

Williamson, B. (2009). Computer games, schools, and young people. A report for educators on using games for learning. Futurelab: Bristol. Retrieved from http://archive.futurelab.org.uk/resources/documents/project_reports/becta/Games_and_L earning_educators_report.pdf 